\title{
Dimethylarginines in chronic renal failure
}

\author{
N Wahbi, R N Dalton, C Turner, M Denton, I Abbs, R Swaminathan
}

Department of

Chemical Pathology,

Guy's, King's and St

Thomas' Medical and

Dental School, Guy's

and St Thomas'

Hospitals, London

SE1 7EH, UK

N Wahbi

R Swaminathan

Department of

Paediatrics, Guy's,

King's and St Thomas'

Medical and Dental

School

R N Dalton

C Turner

Department of

Nephrology, Guy's and

St Thomas' Hospitals,

London SE1 7EH, UK

M Denton

I Abbs

Correspondence to:

Professor Swaminathan,

Guy's, King's and St

Thomas' Medical and Dental

School, Department of

Chemical Pathology, 5th

Floor, North Wing, St

Thomas' Hospital, London

SE1 7EH, UK

r.swaminathan@kcl.ac.uk

Accepted for publication

2 October 2000

\begin{abstract}
Background-Nitric oxide (NO) is a potent chemical mediator involved in many functions. In vivo production of $\mathrm{NO}$ is thought to be regulated by endogenous analogues of L-arginine: asymmetric dimethylarginine (ADMA).

Aim-To examine the effect of renal function and dialysis on the serum concentrations of ADMA and symmetric dimethylarginine (SDMA).

Methods-Blood samples were obtained from nine healthy subjects, patients with renal failure before $(n=17)$ and after haemodialysis $(n=9)$, nine patients on chronic ambulatory peritoneal dialysis (CAPD), and 13 patients with chronic renal failure on conservative treatment. Serum samples were extracted using a solid phase cation exchange column and the extracts were analysed by high performance liquid chromatography (HPLC).
\end{abstract}

Results-Serum concentrations of ADMA in patients with renal failure (mean, $1.04 \mu \mathrm{mol} /$ litre; SD, 0.17) were significantly higher than those of controls (mean, $0.61 \mu \mathrm{mol} / \mathrm{litre}$; SD, 0.13). Haemodialysis significantly decreased the serum concentration by $36 \%$ (before dialysis: mean 0.99 (SD, 0.25) $\mu$ mol/litre; after dialysis: mean, 0.63 (SD, 0.15) $\mu \mathrm{mol} / \mathrm{litre})$. Serum SDMA concentrations were higher in patients with renal failure, and haemodialysis decreased the concentration by $60 \%$. There was no difference in serum arginine concentrations between the groups.

Conclusion-Serum concentrations of ADMA are increased in renal failure and haemodialysis reduces the concentration. (f Clin Pathol 2001;54:470-473)

Keywords: chronic renal failure; dialysis; nitric oxide; arginine; dimethylarginines

Nitric oxide (NO), a potent chemical mediator synthesised from L-arginine by a family of $\mathrm{NO}$ synthases, is involved in many functions including regulation of vascular tone, neurotransmission, and host defence. ${ }^{1}$ In the blood vessels, basal release of NO is important in the maintenance of vascular tone and blood pressure. $^{2}$ Abnormalities in NO production have been implicated in many diseases including hypertension, ${ }^{34}$ pre-eclampsia, ${ }^{56}$ multiple sclerosis, ${ }^{7}$ hypercholesterolaemia, ${ }^{8}$ septic shock, ${ }^{9}$ and renal failure. ${ }^{10} \mathrm{NO}$ is synthesised by the conversion of L-arginine to L-citrulline by the enzyme NO synthase. One of the factors determining the activity of the enzyme is the availability of the substrate L-arginine, which is transported into the cell by an amino acid transporter. The transport of L-arginine can be blocked experimentally by its analogue $\mathrm{N}^{\mathrm{G}}$-methyl-L-arginine (L-NMMA). ${ }^{2}$

It has been suggested that endogenous analogues of L-arginine might be involved in the regulation of the in vivo production of NO. One of these, $\mathrm{N}^{\mathrm{G}}, \mathrm{N}^{\mathrm{G}}$-dimethyl-L-arginine (asymmetric dimethylarginine; ADMA), has been shown to be present in human urine, plasma, ${ }^{10}$ and tissues, ${ }^{11}$ and to be synthesised by endothelial cells. ${ }^{12}$ ADMA has been shown to inhibit NO synthesis in vitro ${ }^{13}$ and has been suggested to play a role in regulating cerebral blood flow. ${ }^{14}$ It has been suggested that the accumulation of ADMA in renal failure might cause inhibition of NO synthase and that this might explain some of the features of renal failure dysfunction. ${ }^{10}$ There have been few studies $^{101516}$ examining the concentration of ADMA in renal failure, and there is disagreement about the findings. In our study, we have examined the effect of renal function and dialysis on the serum concentrations of ADMA, its analogue, symmetric dimethylarginine (SDMA), and arginine.

\section{Methods}

MATERIALS

Amino acids: $\mathrm{N}^{\mathrm{G}}, \mathrm{N}^{\mathrm{G}}$-dimethyl-L-arginine $\mathrm{HCl}$ (ADMA); $\quad \mathrm{N}^{\mathrm{G}}, \mathrm{N}^{\mathrm{G}}$-dimethyl-L-arginine di[phydroxyazobenzene-p'-sulphonate] (SDMA); and L-homoarginine HCL were purchased from Sigma Chemical Co Ltd (Poole, Dorset, UK).

Mobile phase buffer: 1-hexanesulphonic acid, sodium salt; hydrate was from Janssen Chimica (Geel, Belgium). Phosphoric acid was from Sigma Chemical Co Ltd.

Solvents: high performance liquid chromatography (HPLC) grade acetonitrile and methanol were from Rathburn Chemicals Ltd (Walkerbrum, Peebleshire, UK).

Solid phase extraction columns: Varian Bond Elut SCX benzenesulphonic acid (strong cation exchange), $500 \mathrm{mg} / 2.8 \mathrm{ml}$, was purchased from Anachem Ltd (Luton, Bedfordshire, UK). Ammonia solution $\left(\sim 35 \% \mathrm{NH}_{3}\right)$ was from FSA Laboratory Supplies (Loughborough, UK) and was kept at $4^{\circ} \mathrm{C}$. Water was double distilled and the mobile phase buffer was filtered through a $0.22 \mu \mathrm{m}$ pore size disc filter from Millipore Ltd (Watford, Hertfordshire, UK).

\section{SUBJECTS}

Our study was approved by the local ethical committee and informed consent was obtained from all subjects. Blood samples were obtained from nine healthy volunteers (five men and four women; age, 20-50 years), 17 patients with chronic renal failure on regular haemodialysis (eight men and nine women; age, 22-79 
years) before dialysis (mean serum creatinine, $836 \mu \mathrm{mol} /$ litre; range, 453-1812) and in nine immediately after dialysis (mean serum creatinine, $371 \mu \mathrm{mol} /$ litre; range, 202-594), nine patients with chronic renal failure $(\mathrm{CRF})$ on chronic ambulatory peritoneal dialysis (CAPD) (five men and four women; age, 29-78 years; mean serum creatinine, $920 \mu \mathrm{mol} /$ litre; range, 616-1312), and 13 patients with CRF on conservative treatment (eight men and five women; age 36-83 years; mean serum creatinine, $553 \mu \mathrm{mol} /$ litre; range, 256-937).

\section{SAMPLE EXTRACTION}

A $10 \mathrm{ml}$ sample of venous blood was collected in vacutainers with no anticoagulant, centrifuged at $3000 \times g$ for 10 minutes, and serum separated and stored at $-80^{\circ} \mathrm{C}$ until analysis. A $3 \mu \mathrm{l}$ aliquot of $20 \mathrm{mmol} /$ litre homoarginine (internal standard) was added to $3 \mathrm{ml}$ of serum, mixed, and the sample extracted using Bond Elut-SCX solid phase columns (Jones Chromatography Ltd, Glamorgan, Wales, UK). The columns were first solvated and equilibrated by successively passing through $2.8 \mathrm{ml}$ each of methanol, $50 \%$ ammonia/ methanol, and distilled water. After passing the sample through, the column bed was washed three times with $2.8 \mathrm{ml}$ water and the dimethylarginines were eluted with $2 \times 1.4 \mathrm{ml}$ of $50 \%$ ammonia/methanol. The eluate was immediately taken to dryness at $65^{\circ} \mathrm{C}$ under nitrogen, the residue reconstituted in $75 \mu \mathrm{l}$ water and stored at $4^{\circ} \mathrm{C}$ until required for further analysis by HPLC. All stages of the solid phase extraction were processed using a bench top centrifuge (Mistral 2000) set at $250 \times g$ for two minutes, except for the washing stage, which was at a higher speed of $12000 \times g$ for two minutes.

MEASUREMENT OF DIMETHYLARGININES

ADMA and SDMA were separated by reversed phase ion pair HPLC, as described previously by MacAllister et al. ${ }^{17}$ The analysis was carried out on a Hewlett-Packard (Stockport, Cheshire, UK) 1090 Series II Win HPLC system, which includes a diode array detector and an HPLC 3D Chemstation (DOS series) PC for control of the whole apparatus and data processing. Separation was performed on a $5 \mu \mathrm{m}$ Spherisorb ODS column $(100 \times 4.6 \mathrm{~mm}$ (internal diameter)) and a cartridge ODS guard column $(10 \times 3.2 \mathrm{~mm}$ (internal diameter)), both from Hichrom Ltd (Reading, Berkshire, UK). A $20 \mu \mathrm{l}$ volume of the extracts was injected and the mobile phase was a mixture of $0.025 \mathrm{M}$ phosphate solution (1.71 $\mathrm{ml}$ of phosphoric acid added to $900 \mathrm{ml}$ of water and adjusted to $\mathrm{pH} 5.0$ with $5 \mathrm{M}$ potassium hydroxide), $0.01 \mathrm{M}$ hexanesulphonic acid $(1.88 \mathrm{~g} /$ litre $)$, and $1 \%$ (vol/vol) acetonitrile. The flow rate was $1 \mathrm{ml} /$ minute and the ultra violet detector was set at $200 \mathrm{~mm}$.

In preliminary studies, extracts of samples from patients with CRF where chromatographed as described and fractions eluting at the retention times of standard SDMA and ADMA were collected and reanalysed on an amino acid analyser (Hewlett Packard) to confirm the identity.

The concentrations of arginine and dimethylarginine were calculated from the areas of the peaks compared with that of standards, after correction for the internal standard.

STATISTICS

The data are presented as the mean (SD) and compared by Student's $t$ test for paired or unpaired observations.

\section{Results}

The mean (SD) recovery of ADMA, SDMA, and arginine added to serum $(n=6)$ before extraction was $105 \%(6.2 \%), 99 \%$ (5.5\%), and $87 \%(9.2 \%)$, respectively. The interassay coefficient of variation $(\mathrm{CV})$ values $(n=6)$ for the measurement of these amino acids were $4.4 \%$, $4.4 \%$, and $5.3 \%$, respectively.

Figure 1A shows the separation of standard ADMA and SDMA $(2.5 \mu \mathrm{mol} / \mathrm{litre})$ and of homoarginine $(20 \mu \mathrm{mol} /$ litre $)$ used as an internal standard. Figure $1 \mathrm{~B}$ shows a typical chromatographic profile of serum from a healthy subject and fig 1C shows the profile of a patient with CRF before haemodialysis. The peaks eluting at the same retention time as standard ADMA and SDMA were isolated and identified as ADMA and SDMA using an amino acid analyser.

Serum concentrations of ADMA, SDMA, and arginine in healthy volunteers and the different groups of patients with CRF are shown in table 1. The serum concentration of ADMA in the control group was $0.61(0.13) \mu \mathrm{mol} /$ litre and in all the renal failure groups the serum concentration of ADMA was significantly raised. Haemodialysis significantly decreased the serum concentration of ADMA by $36 \%$ and the mean concentration of ADMA after dialysis was similar to that in the healthy controls (table 1).

The serum concentration of SDMA in the healthy subjects was less than that of ADMA and the ratio of ADMA to SDMA was 1.49. The serum concentration of SDMA in all the renal failure groups was significantly raised (table 1). After haemodialysis, the concentration fell by $60 \%$ but was still significantly higher than in healthy subjects. The serum concentration of arginine in the healthy subjects and all groups of patients with CRF was almost the same, with the mean ranging between 100 and $130 \mu \mathrm{mol} /$ litre (table 1), and there were no significant differences between the patient groups and healthy subjects. There was no correlation between the creatinine concentration and ADMA or SDMA concentrations in any of the groups.

\section{Discussion}

An HPLC method based on that described by MacAllister and colleagues ${ }^{17}$ was developed for the measurement of dimethylarginines. The dimethylarginines required an extraction step using a Bond Elut SCX column to remove interfering substances and to concentrate the samples. Using this method, the recoveries of added ADMA and SDMA were nearly $100 \%$. 

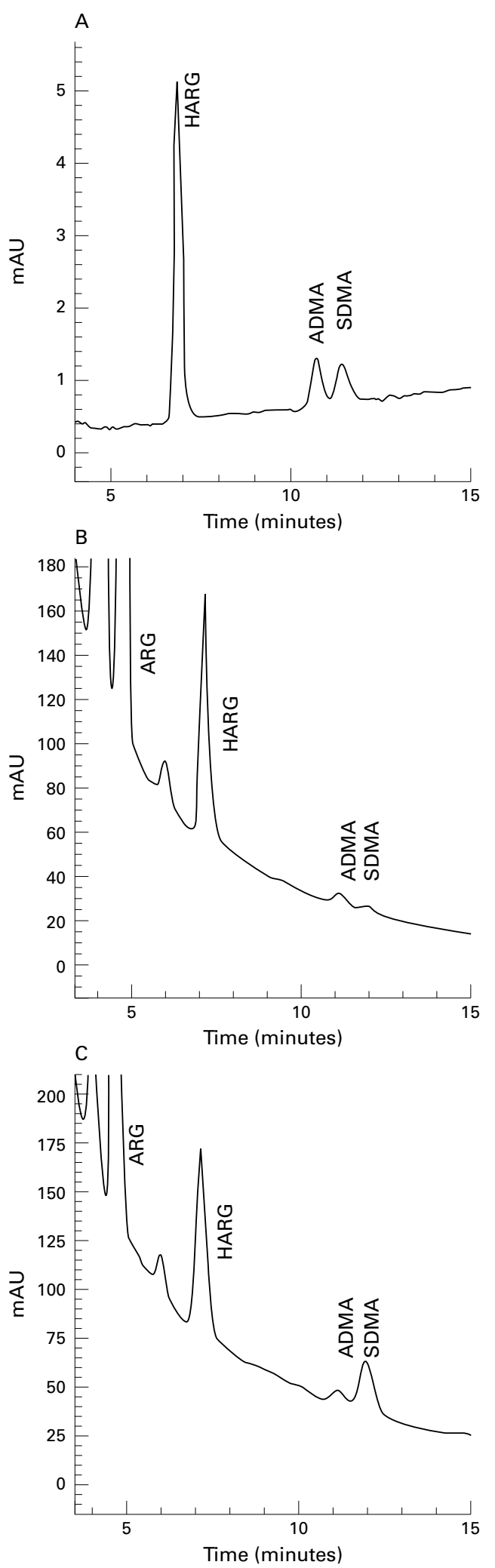

Figure 1 Ion pair chromatograms of $A D M A$ and SDMA in $(A)$ aqueous standard (2.5 $\mu \mathrm{mol} /$ litre of ADMA/SDMA, 20 umol/litre of homoarginine), (B) serum from a control subject, and (C) pre-dialysis serum. ARG, arginine; $H A R G$ homoarginine; $A D M A$, asymmetric dimethylarginine; SDMA, symmetric dimethylarginine.

The method had good precision. Reported concentrations of serum ADMA in healthy subjects vary widely: $0.10 \mu \mathrm{mol} /$ litre, ${ }^{18} 0.36 \mu \mathrm{mol} /$ litre, ${ }^{15}$
$0.36 \mu \mathrm{mol} /$ litre, ${ }^{16}$ and $0.41 \mu \mathrm{mol} / \mathrm{litre},{ }^{19}$ all of which are lower than we found in our study $(0.61 \mu \mathrm{mol} / \mathrm{litre})$. In these studies, no data are given for the recovery of added ADMA, and it is possible that the lower concentrations reported might reflect loss of dimethylarginines during extraction. Furthermore, in some methods an internal standard was not used during the chromatography step ${ }^{18}$ and this might further reduce the measured values.

The concentration of total dimethylarginines (ADMA and SDMA) in the control group was $1.02 \mu \mathrm{mol} /$ litre, which is similar to that reported by Vallance et $a l,{ }^{10}$ although they did not report the concentration of ADMA separately in healthy subjects. The concentration of ADMA found in healthy pigs was reported to be $3.4 \mu \mathrm{mol} /$ litre, a value nearly five times that in humans. ${ }^{20}$ The wide variation in ADMA concentrations in healthy subjects suggests that further studies are required to standardise the methodology and determine the normal concentration of ADMA in healthy subjects. We studied only nine normal subjects, and a much higher number would be required to determine factors influencing ADMA concentrations, in particular the effects of age.

It has been suggested that some of the features of CRF might result from the inhibition of NO production, ${ }^{10}$ and uraemic plasma has been shown to inhibit NO synthase activity in murine endothelial cells. ${ }^{21}$ Fickling and colleagues ${ }^{12}$ have shown that human endothelial cells in culture can synthesise ADMA. MacAllister and colleagues ${ }^{13}$ showed that guanidino and uraemic compounds have a dose dependent inhibitory effect on NO synthesis. At a concentration of $100 \mu \mathrm{mol} /$ litre, ADMA inhibited NO synthesis by $31.8 \%$. ADMA also caused reversal of bradykinin induced relaxation of human saphenous veins and the EC50 for ADMA was $17.9 \mu \mathrm{mol} /$ litre. These authors concluded that the guanidino compounds that accumulate in renal failure are potent inhibitors of NO synthesis. The in vitro study of Arese et al showed that the EC50 of ADMA needed for inhibition of NO was higher than the concentration of ADMA found in $\mathrm{CRF}^{21}$ The mean (SD) concentration of ADMA in predialysis samples was $0.99(0.25) \mu \mathrm{mol} /$ litre, which is 1.6 times that seen in healthy subjects. The concentration in patients on CAPD and in conservatively treated patients with CRF were similar (table 1). Values reported by MacAllister and colleagues ${ }^{15}$ in end stage renal disease and that by Anderstam and colleagues ${ }^{16}$ in patients on dialysis were 2.5 and 1.9 times that of healthy controls, respectively. However, in our study the concentration of SDMA in predialysis patients was four times higher (4.53 $v 0.99 \mu \mathrm{mol} /$ litre). The sum of ADMA and SDMA found in our predialysis patients $(5.5 \mu \mathrm{mol} /$ litre $)$ was lower than that reported by Vallance et al (mean, 8.7; SD, $0.7 \mu \mathrm{mol} / \mathrm{litre}),{ }^{10}$ and the ratio of ADMA to SDMA (0.21) was similar to that reported previously. ${ }^{15}{ }^{16}$ Dialysis reduced the concentration of ADMA to that found in healthy subjects, whereas the SDMA concentration decreased but did not reach control values (table 1). It is also interesting to note that the serum arginine 
Table 1 Serum concentrations of dimethylarginine and arginine in healthy subjects and in patients with renal failure

\begin{tabular}{llll}
\hline & \multicolumn{2}{l}{ Serum concentration $(\mu \mathrm{mol} / \mathrm{l})$} \\
\cline { 2 - 4 } & ADMA & SDMA & Arginine \\
\hline Healthy subjects $(\mathrm{n}=9)$ & $0.61(0.13)$ & $0.41(0.12)$ & $118(17.5)$ \\
Predialysis $(\mathrm{n}=17)$ & $0.99(0.25)^{\star \star}$ & $4.53(1.54)^{\star \star}$ & $116(25.2)$ \\
Post dialysis & $0.63(0.15)^{\star}$ & $2.95(1.06)^{\star} \dagger$ & $104(26.7)$ \\
CAPD $(\mathrm{n}=9)$ & $0.96(0.31)^{\star}$ & $4.01(2.22)^{\star}$ & $128(23.6)$ \\
CRF $(\mathrm{n}=13)$ & $1.04(0.17)^{\star}$ & $2.47(0.95)^{\star}$ & $125(27.8)$ \\
\hline
\end{tabular}

Results are mean $(\mathrm{SD})$

${ }^{\star} \mathrm{p}<0.01$ and ${ }^{\star \star} \mathrm{p}<0.000$. Significantly different from healthy controls.

$\mathrm{tp}<0.01$. Significantly different from predialysis values by paired $t$ test.

ADMA, asymmetrical dimethylarginine; SDMA, symmetrical dimethylarginine.

concentration was not different in our patients with CRF, whereas others have reported lower arginine concentrations in $\mathrm{CRF} .{ }^{10}$ Although the concentration of ADMA varies in different studies, the ratio of ADMA in renal failure to that in controls is similar: approximately 2 .

The greater accumulation of SDMA than of ADMA (the ratio of ADMA to SDMA decreased from 1.5 in controls to 0.21 in predialysis samples) has been observed before..$^{1519}$ This has been suggested to result from selective metabolism of ADMA but not SDMA. ${ }^{15}$ Renal clearance of SDMA and ADMA change in parallel, ${ }^{19}$ and cannot account for the greater rise in SDMA. The importance of this greater increase in SDMA is not clear because no effects of SDMA have been demonstrated in vitro. ${ }^{10}$

Although our study shows that serum ADMA is only moderately raised and is at a concentration that is lower than that necessary to inhibit NO, it is possible that the concentration of ADMA near the endothelial cells is much higher. Thus, our study cannot exclude the possibility that ADMA might have a role in mediating the concentration of $\mathrm{NO}$ in CRF.

We conclude that the concentration of ADMA is increased in renal failure and dialysis reduces the concentration.

We would like to thank Dr S Bird for performing the analysis on the amino acid analyser and Mrs C Morgan for typing the manuscript.
1 Moncada S, Higgs A. The L-arginine-nitric oxide pathway. N Engl f Med 1994;329:2002-12.

2 Rees DD, Palmer RM, Moncada S. Role of endotheliumderived nitric oxide in the regulation of blood pressure. Proc Natl Acad Sci U S A 1989;86:3375-8.

3 Chen PY, Sanders PW. L-Arginine abrogates salt-sensitive hypertension in Dahl/Rapp rats. F Clin Invest 1991;88: 1559-67.

4 Matsuoka $\mathrm{H}$, Itoh $\mathrm{S}$. Kimoto $\mathrm{M}$, et al. Asymmetrical dimethylarginine, an endogenous nitric oxide synthase inhibitor, in experimental hypertension. Hypertension 1997; 29:242-7.

5 Lopez-Jaramillo P, Narvaez M, Calle A, et al. Cyclic guanosine 3',5' monophosphate concentrations in pre-eclampsia: effects of hydralazine. Br f Obstet Gynaecol 1996;103:33-8.

6 Fickling SA, Williams D, Vallance P, et al. Plasma concentrations of endogenous inhibitor of nitric oxide synthesis in normal pregnancy and pre-eclampsia. Lancet 1993;342:242-3.

7 Rawal N, Lee YJ, Whitaker JN, et al. Urinary excretion of NG-dimethylarginines in multiple sclerosis patients: preliminary observations. $\mathcal{F}$ Neurol Sci 1995;129:186-91.

8 Boger RH, Bode-Boger SM, Szuba A, et al. Asymmetric dimethylarginine (ADMA): a novel risk factor for endotheial dysfunction. Its role in hypercholesterolaemia. Circulation 1998;98:1842-7.

9 Hotchkiss RS, Karl IE, Parker JL, Adams HR. Inhibition of NO synthesis in septic shock. Lancet 1992;339:434-5.

10 Vallance P, Leone A, Calver A, et al. Accumulation of an endogenous inhibitor of nitric oxide synthesis in chronic renal failure. Lancet 1992;339:572-5.

11 Kimoto $M$, Whitley GS, Tsuji $\mathrm{H}$, et al. Detection of NG,NG-dimethylarginine dimethylaminohydrolase in human tissues using a monoclonal antibody. 7 Biochem 1995; 117:237-8.

12 Fickling SA, Leone AM, Nussey SS, et al. Synthesis of $\mathrm{N}^{\mathrm{G}}$, $\mathrm{N}^{\mathrm{G}}$ dimethylarginine by human endothelial cells. Endothelium 1993;3:137-40.

13 MacAllister RJ, Whitley GST, Vallance P. Effects of guanidino and uraemic compounds on nitric oxide pathways. Kidney Int 1994;45:737-42.

14 Faraci FM, Brian JE, Jr, Heistad DD. Response of cerebral blood vessels to an endogenous inhibitor of nitric oxide synthase. Am $\mathcal{7}$ Physiol 1995;269:H1522-7.

15 MacAllister RJ, Rambausek MH, Vallance P, et al. Concentration of dimethyl-L arginine in the plasma of patients with end-stage renal failure. Nephrol Dial Transplant 1996;11:2449-52.

16 Anderstam B, Katzarski K, Bergstrom J. Serum levels of $\mathrm{N}^{\mathrm{G}} \mathrm{N}^{\mathrm{G}}$ dimethyl-L-arginine, a potential endogenous nitric oxide inhibitor in dialysis patients. 7 Am Soc Nephrol 1997; 8:1437-42.

17 MacAllister RJ, Fickling SA, Whitley GSJ, et al. Metabolism of methylarginines by human vasculature; implications for the regulation of nitric oxide synthesis. $\mathcal{F}$ Pharmacol 1994;112:43-8.

18 Goonasekera CD, Rees DD, Woolard P, et al. Nitric oxide synthase inhibitors and hypertension in children and adolescents. F Hypertens 1997;15:901-9.

19 Al Banchaabouchi M, Marescau B, Possemiers I, et al. $\mathrm{N}^{\mathrm{G}}$, $\mathrm{N}^{\mathrm{G}}$-Dimethylarginine and $\mathrm{N}^{\mathrm{G}}, \mathrm{N}^{1 \mathrm{G}}$-dimethylarginine in renal insufficiency. Eur f Physiol 2000;439:524-31.

20 Aneman A, Backman V, Snygg J, et al. Accumulation of an endogenous inhibitor of nitric oxide synthase during graded hemorrhagic shock. Circulatory Shock 1994;44:111-14.

21 Arese M, Strasly M, Ruva C, et al. Regulation of nitric oxide synthesis in uraemia. Nephrol Dial Transplant 1995;10: 1386-91. 